\title{
Overlapped joints in Textile Reinforced Concrete with UHPC matrix: An experimental investigation
}

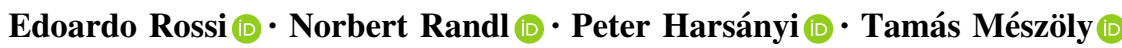

Received: 18 December 2020/ Accepted: 16 June 2021 / Published online: 9 July 2021

(C) The Author(s) 2021

\begin{abstract}
When producing a Textile Reinforced Concrete structure or element, joining separate textile layers might be a necessity, driven for example by the limited dimensions of commercially available fabrics. A possible way of producing such joints is by overlapping different textile sheets. Overlapped joints, however, need to be cast with particular attention since they might represents weak elements of the structure, leading to premature failure. An experimental campaign was performed, aimed at identifying the effects of a symmetric vs non-symmetric arrangement of the textile fabrics within the overlapping length and tensile characteristics of the matrix on such type of joints. Fifteen specimens, produced using a fully epoxy impregnated carbon textile fabric and an Ultra High Performance Concrete (UHPC) matrix, were tested under tension in a uniaxial setup and measurements were performed using a Digital Image Correlation system. The in-plane and out-of-plane
\end{abstract}

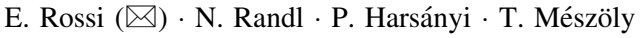
Faculty of Civil Engineering and Architecture, Carinthia University of Applied Sciences, Villacher Straße 1, 9800 Spittal an der Drau, Austria e-mail: e.rossi@cuas.at

N. Randl

e-mail: n.randl@cuas.at

P. Harsányi

e-mail: p.harsanyi@cuas.at

T. Mészöly

e-mail: t.meszoely@cuas.at
}

behaviour of each specimen was studied. The results highlight the importance of producing symmetric elements as well as the beneficial effects that the admixture of short dispersed steel fibres to the cementitious matrix provide to such kind of joints

Keywords Textile Reinforced Concrete . Overlapped joints · Ultra-High Performance Concrete $\cdot$ Experimental testing $\cdot$ Digital Image Correlation

\section{Introduction}

Textile reinforced concrete (TRC) is a new class of concrete composite materials that has drawn the attention of both the scientific community and the construction industry. Such material, also known as textile reinforced mortar (TRM), fabric reinforced cementitious matrix (FRCM) or steel reinforced grout (SRG), consists of the combination of a fabric made of high strength material (carbon, glass, PBO, high strength steel, etc.), which acts as tensile reinforcement and a cementitious matrix, used to bind the fabric and, depending on the application, to carry compressive stresses.

In the last decades TRC has been extensively studied either as a material for thin concrete structures (sandwich elements, shell elements, vaulted 
structures, etc.) [1]-[5] or as strengthening and retrofitting solutions for existing constructions, mainly made out of reinforced concrete [6]-[12] or masonry [13]-[18].

The mechanical properties and the behaviour of TRC elements have been extensively studied using different testing methods. The most common is the direct tensile test [19]. Such test, even if influenced by the clamping system [20], tends to provide a characteristic behaviour consisting of three stages:

a. The first stage is characterized by the combined response of textile fabric and cementitious matrix; this stage is generally the one that exhibits the highest stiffness.

b. The second stage is characterized by extensive cracking of the specimen, visible as a series of force drops; such phenomenon leads to a reduction of the stiffness.

c. The third stage is characterized by an increase in stiffness compared to the previous one and it represents the behaviour of the fabric reinforcement.

Another recent, yet common, test is used to characterize the bonding properties of TRC cast against a substrate [21]. Such test provides useful information on the effectiveness of TRC elements used as repairing or retrofitting solutions and can clearly point out the weakest part of the system, since it may result in different failure modes. Furthermore, several studies concentrated on the bond properties of the textile within the cementitious matrix (see for example [22]-[24]).

Little attention, however, has been given to overlapped textile joints. Such type of constructive details are often unavoidable and, if not appropriately designed, they may lead to undesired behaviours and premature failures. Lorentz and Ortlepp were among the first to test overlapped textile joints [25]. They analysed several overlapping in symmetrical setups. From their work they concluded that the minimum overlapping length needed for a full stress transfer between textile sheets, was the same as the developing length (also known as anchorage length) of one textile. Furthermore, they stated that the cracking of the matrix within the overlapping length had only a marginal effect. Their results were then further analysed by Azzam and Richter by means of numerical simulations [26]. More recently, Donnini et al. tested several TRC plates with varying overlapping lengths in tension [27]. They reported that for a $100 \mathrm{~mm}$ overlapping length the specimens failed due to slippage of the fabric at the overlapping interface. The interface was also characterised by a shear crack running along the overlapping length in the longitudinal direction. For longer overlapping lengths $(150 \mathrm{~mm}$ and $200 \mathrm{~mm})$ they reported failure due to rupture of one of the rovings. Vlach et al. tested plates with a fabric overlapping length of $35 \mathrm{~mm}$ and $55 \mathrm{~mm}$ [28]. They always observed failure in the concrete matrix surrounding the overlapping zone and point out the necessity for an accurate positioning of the textile to avoid undesired eccentricity that might reduce the strength of such kind of joints.

In order to further investigate the behaviour of overlapped textile joints, several specimens were produced and tested in the Civil Engineering lab of Carinthia University of Applied Sciences. More in detail, the experimental program was meant to highlight how geometrical details, such as textile layout and overlapping length and mechanical characteristics of the cementitious matrix affect the performance of overlapped textile joints. While, from a design perspective, a joint that can be assimilated to a continuous textile fabric is desirable, the tested overlapping length was designed to exhibit a lower performance, thus highlighting the behaviour associated with a failure of the connection rather than failure of the textile. Understanding the behaviour of this type of structural details is an important step towards a more rational design of TRC elements and structures, which can lead to a more efficient utilization of the high-strength fabrics while reducing the risk of premature failures. The results show the importance of avoiding, whenever possible, the production of nonsymmetric layouts within the thickness of the element. Furthermore, an increase in the mechanical characteristics of the cementitious matrix proved to have a strong influence on the overall behaviour of the specimens, suggesting to add short dispersed steel fibres to the concrete mix in order to obtain a very high performance increase.

\section{Geometry and Test setup}

An experimental test campaign consisting of 15 specimens, subdivided in 5 different configurations 
(each configuration was tested three times), was performed in order to investigate the effect of different geometrical configurations, overlapping lengths and mechanical characteristics of the matrix. Each specimen had an overall length of $600 \mathrm{~mm}$, a width of $120 \mathrm{~mm}$ and a thickness of approximately $20 \mathrm{~mm}$. The textiles were arranged in two different configurations, a symmetric one, consisting of two layers placed in the bottom part of the specimens and a single layer in the top part and a non-symmetric one, where in the bottom plate only one textile layer was present. The overlapping was realised extending the two central rovings of the top textile layer for a length of $75 \mathrm{~mm}$ and $100 \mathrm{~mm}$ over the bottom one. Furthermore, a notch was cut in the middle of the specimens to force the two plates to interact only by means of the overlapped textile. The distance between two adjacent textile layers was approximately $5 \mathrm{~mm}$. Furthermore, three specimens were produced adding short dispersed steel fibres to the concrete matrix in order to increase its tensile properties. Such test setup was designed to ensure that the top and bottom plates were only connected by means of the overlapped textile. While this configuration obviously deviates from what would generally be encountered in practice, a full-width overlap would have resulted in several drawbacks related to the location of the first crack, location of the (eventual) failure of the textile and effects related to the in-plane bending caused by imperfections. In particular, the presence of only two rovings in the overlapping zone, combined with the big notch that was cut on the specimens, forced the first crack to appear at the beginning of the overlapping zone separating the two plates. In addition, having only two overlapped rovings reduced the effect of in-plane bending of the specimens caused by geometrical imperfections. Lastly, such configuration also ensures that, in case of textile rupture, failure happens at the beginning of the overlapped zone, enabling more traditional sensors (e.g. LVDTs) to be used and removing the need of necessarily using a DIC system. A schematic representation of the specimens can be found in Fig. 1, while a summary of the tested specimens, together with the cementitious material used, the overlapping length and the geometrical arrangement can be found in Table 1. The specimens' IDs reflect the varying parameters: the first letter(s) refer to the symmetric (S) or non-symmetric (NS) configuration; the first number refers to the overlapping length in $\mathrm{cm}\left(10^{-1} \mathrm{~mm}\right)$; the last number enumerates the replication of a test with identical parameters. When UHPFRC was used, two additional letters (FR, fibre-reinforced) are added to the ID. As an example, NS-7.5-1 refers to the first tested specimen with a non-symmetric configuration and $75 \mathrm{~mm}$ overlapping length.

The textile used in the specimens was a commercially available bidirectional carbon grid with the rovings distanced $25 \mathrm{~mm}$ from each other (measured from the roving's axis) and with a cross sectional area of $3.62 \mathrm{~mm}^{2}$. The tensile strength of the rovings was $3100 \mathrm{MPa}$ while Young's Modulus was greater than $220 \mathrm{GPa}$, according to its technical sheet [29]. The cementitious matrix consisted of an Ultra High Performance Concrete (UHPC), further developed from an existing self-made recipe [30], which was successfully used in other applications [31, 32]. Most of the specimens (12 out of 15) were produced without the addition of short dispersed steel fibres. The remaining three specimens, instead, were cast adding 2 vol\% of steel fibres characterized by a length of $5 \mathrm{~mm}$, a diameter of $0.15 \mathrm{~mm}$, resulting in an aspect ratio of 33.3. A similar combination was already tested in a previous experimental campaign and showed promising results [33]. To distinguish the two materials the second one is addressed as Ultra High Performance Fibre Reinforced Concrete (UHPFRC). The compressive strength of the two cementitious materials was tested 28 days after casting on $100 \times 100 \times 100 \mathrm{~mm}$ cubes, providing an average compressive strength of $150.8 \mathrm{MPa}$ for UHPC and 160.0 for UHPFRC. The mean splitting tensile strength of the two materials, measured on $100 \times 200 \mathrm{~mm}$ cylinders, was $6.8 \mathrm{MPa}$ and $13.5 \mathrm{MPa}$, respectively.

The specimens were clamped to the testing frame via four steel plates, two per end, attached to the machine with two cylindrical hinges, allowing inplane rotation. The clamping length was $120 \mathrm{~mm}$ and the steel plates were fixed together using 8 bolts per side, each torqued at $60 \mathrm{Nm}$ (Fig. 2). The measuring equipment consisted of a Digital Image Correlation (DIC) system composed of four 9 Megapixel cameras, two per side. The suitability of such measuring equipment was already tested and validated in previous research activities [32, 34]. The tests were performed under displacement control conditions, with a displacement rate set to $0.2 \mathrm{~mm} / \mathrm{min}$. 


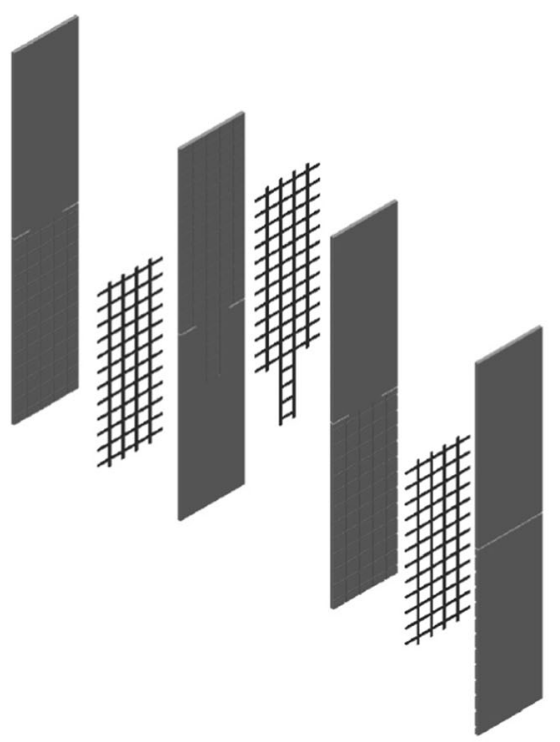

(a) Exploded view

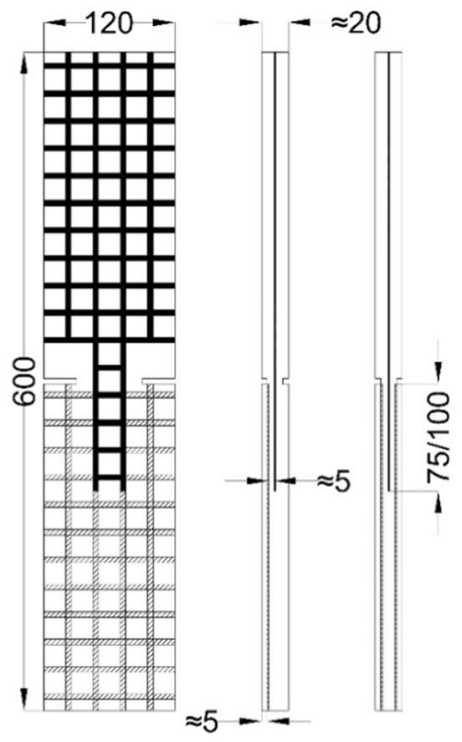

(b) Technical drawing

Fig. 1 Schematic representation of the specimens

Table 1 Specimens configuration

\begin{tabular}{llcl}
\hline ID & Matrix & Overlapping length $(\mathrm{mm})$ & Configuration \\
\hline NS-7.5-1 & UHPC & 75 & Non-symmetric \\
NS-7.5-2 & UHPC & 75 & Non-symmetric \\
NS-7.5-3 & UHPC & 75 & Non-symmetric \\
NS-10-1 & UHPC & 100 & Non-symmetric \\
NS-10-2 & UHPC & 100 & Non-symmetric \\
NS-10-3 & UHPC & 100 & Non-symmetric \\
S-7.5-1 & UHPC & 75 & Symmetric \\
S-7.5-2 & UHPC & 75 & Symmetric \\
S-7.5-3 & UHPC & 75 & Symmetric \\
S-10-1 & UHPC & 100 & Symmetric \\
S-10-2 & UHPC & 100 & Symmetric \\
S-10-3 & UHPC & 100 & Symmetric \\
NS-FR-10-1 & UHPFRC & 100 & Non-symmetric \\
NS-FR-10-2 & UHPFRC & 100 & Non-symmetric \\
NS-FR-10-3 & UHPFRC & 100 & Non-symmetric \\
\hline
\end{tabular}

\section{Results}

\subsection{Failure modes and crack patterns}

Three failure modes were observed in the test campaign. The first one in non-symmetric configurations, exhibited spalling of the concrete cover on the bottom side of the specimen where there was no textile layer (Figs. 3 and 4a). Two inclined cracks propagated from the two central rovings until they reached the outer part of the specimen; at this point the concrete covering the overlapped rovings was expelled, leading to failure. The symmetric specimens, instead, failed by textile pullout (Figs. 3 and $4 \mathrm{~b}$ ). As before, two diagonal cracks originating from the central rovings can be observed, however, the presence of a textile layer prevented such cracks from reaching the closest outer face of the specimen. The cracks, instead, 


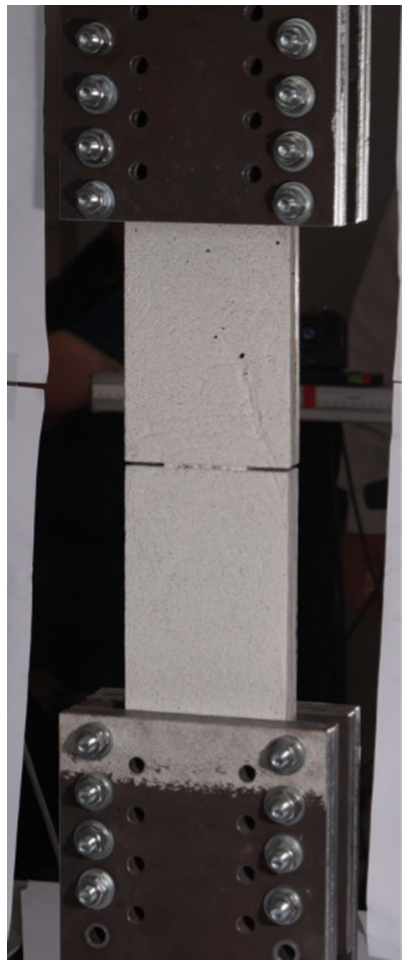

Fig. 2 Test setup

propagated in the plane of the textile, reaching the small sides of the specimen and causing a local delamination of the outer textile layer. It is important to mention that such crack pattern is influenced by the chosen geometry of the specimens. In the case of textiles overlapped over their full width, the diagonal cracks may be characterized by a different inclination (eventually being replaced by a splitting crack running along the plane of the central textile) and reach the side faces (thickness) of the specimens instead of the front one (width). Such difference may thus result in a smaller cracking area and, consequently, in a lower failure load. This, however, strongly depends on each TRC configuration in terms of thickness and distance between the edge of the element and the most external roving. Also the fibre-reinforced specimens failed by textile pullout (Fig. 4c), except specimen NS-FR10-2 that failed due to rupture of the textile. In these specimens, diagonal cracks, as in the other nonsymmetric ones, tried to propagate to the surface but, due to the enhanced tensile properties of UHPFRC, the spalling of the concrete cover was prevented.

Such crack pattern clearly shows that failure of the specimens was caused by splitting phenomena induced by stress transfer between the axially loaded rovings and the surrounding cementitious matrix [35], resulting in the activation of the mechanisms observed in the different failure modes (i.e. spalling and pullout). This phenomenon can be particularly relevant in TRC structures due to their limited thicknesses, thus resulting in low concrete covers and the absence of

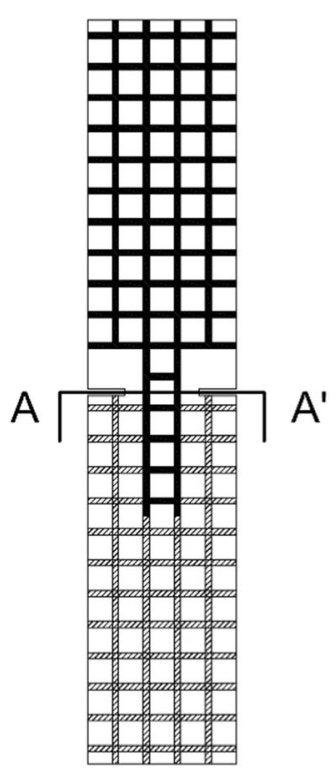

\section{Section A-A'}
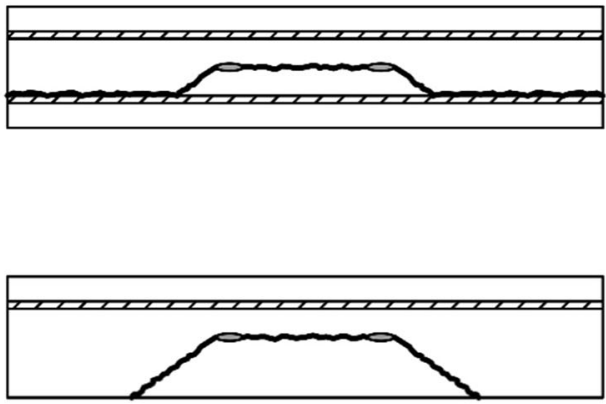

Fig. 3 Schematic representation of crack patterns 


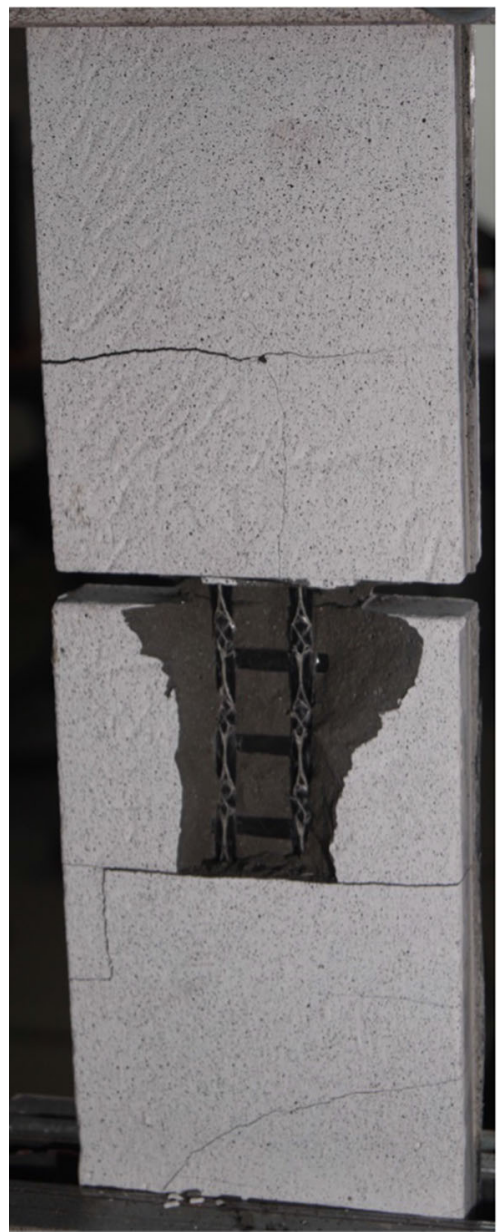

(a) NS-10-1

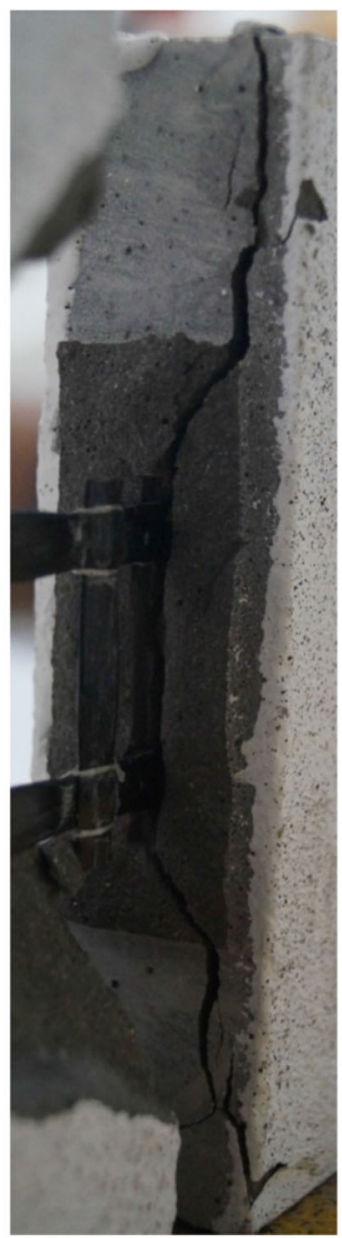

(b) S-10-1

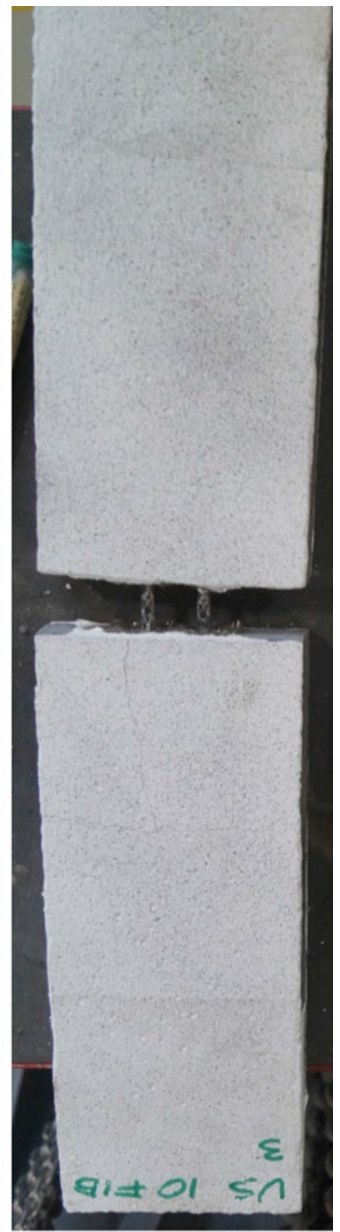

(c) NS-FR-10-3

Fig. 4 Crack pattern after failure of the different kind of specimens

transversal reinforcement. Both of them are key factors in the achievement of a good splitting resistance; their simultaneous absence makes such material prone to this kind of failure.

Analysing the crack patterns of the specimens prior to failure, highlighted by the DIC evaluation (Fig. 5), it is possible to see that the non-symmetric specimens exhibited diffuse cracking on the whole plate length. Furthermore, the two diagonal cracks that led to spalling of the concrete cover are clearly visible (Fig. 5a). Also the symmetric specimens showed diffuse cracking and two sub-vertical cracks in the overlapping region, which, however, due to the presence of the additional textile layer, could not reach the cracks that originated from the two central rovings, thus preventing spalling of the concrete cover
(Fig. 5b). In contrast, the specimens produced with UHPFRC hardly showed any cracks. Only small hairline cracks could be observed in the overlapping region, running nearly vertically from the centre towards the end of the plates (Fig. 5c).

\subsection{Force - Crack opening behaviour}

Each specimen was analysed monitoring the relative displacement of the top and bottom plate, i.e. crack opening, using a virtual sensor in the DIC evaluation. The results are plotted in Fig. 6. As can be seen, all specimens failed at similar crack opening values. Specimens NS-7.5 and NS-10 failed at similar loads and presented noticeable scatter in terms of crack opening at the maximum load, in particular in the case 


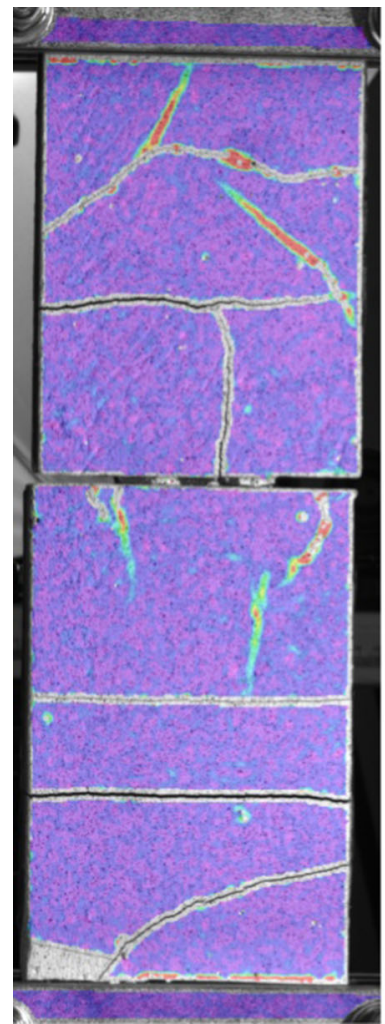

(a) NS-10-1

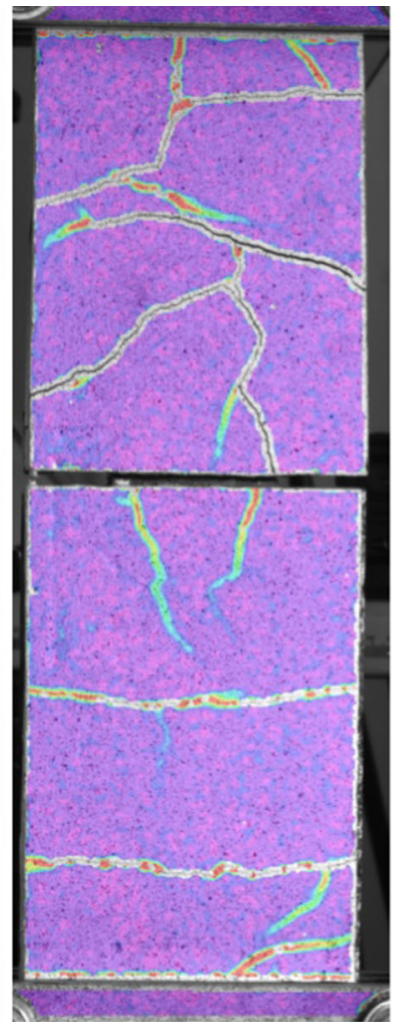

(b) S-10-1

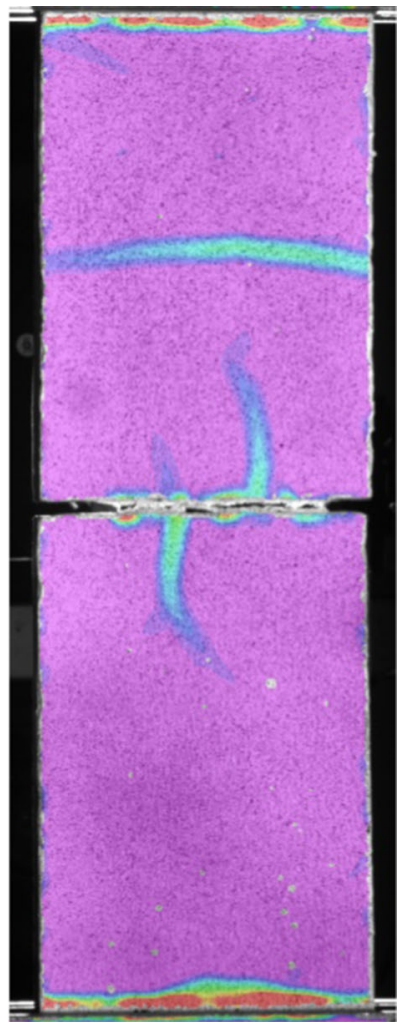

(c) NS-FR-10-3

Fig. 5 DIC crack pattern prior to failure of the different kind of specimens

of NS-10 specimens. The effect of the distributed cracking is also visible as force drops that tend to be quite high in absolute value. The symmetric specimens present a strong reduction of the scatter. Once again, several force drops associated with the distributed cracking of the specimens are visible, however, their intensity is reduced. Furthermore, the symmetric configuration enabled specimens S-10 to achieve higher loads. The fibre-reinforced specimens exhibited the overall best behaviour. Specimen NS-FR10-2 exhibited a premature failure due to rupture of one of the two rovings. This was probably due to some inherent defect of the textile such as a reduced crosssectional area or a deviation from a perfectly straight configuration, which caused one of the two rovings to experience higher stresses. The other two specimens of this series showed very little scatter and a strong increase in the residual load carrying capacity. Furthermore, no sudden load drops are visible in the curves associated with such test series, reinforcing what was already observed.

\subsection{Out of plane displacement}

The out of plane displacement of the specimens was monitored to assess the influence of the internal moment, aligned with the transversal rovings, generated by the non-symmetric configuration. Four virtual sensors were placed in the middle of each specimen near the notch, one per side (top, bottom, front and back, see Fig. 7); the out of plane displacement was then calculated by averaging the values measured by each sensor.

The results are reported in Fig. 8. The specimens produced with UHPC and characterised by a nonsymmetric configuration were subjected to a strong out of plane displacement, reaching values above $4 \mathrm{~mm}$ with respect to the original configuration. When a symmetric configuration was instead used, the specimens tended to deform in their plane, exhibiting very small out of plane displacements, likely caused by some imperfection in the casting process or by some unavoidable misalignment of the clamping 


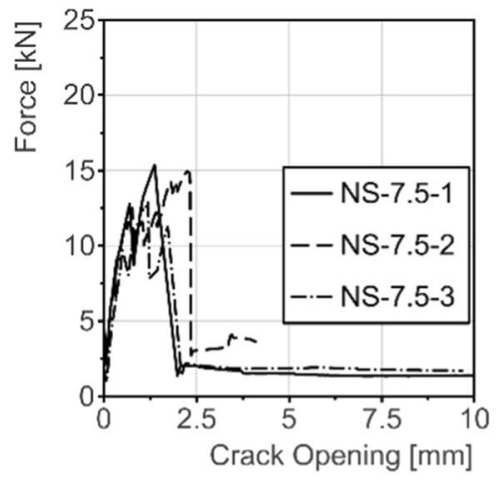

(a) NS-7.5

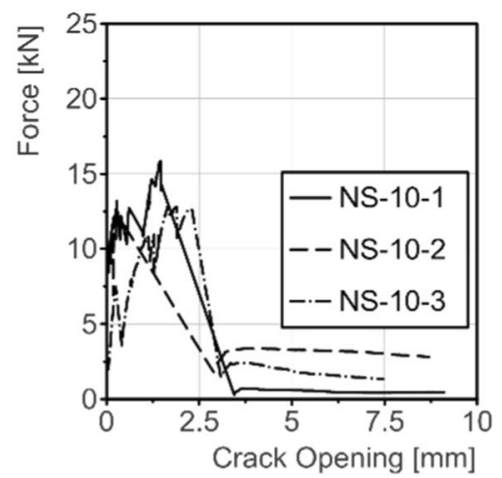

(b) NS-10

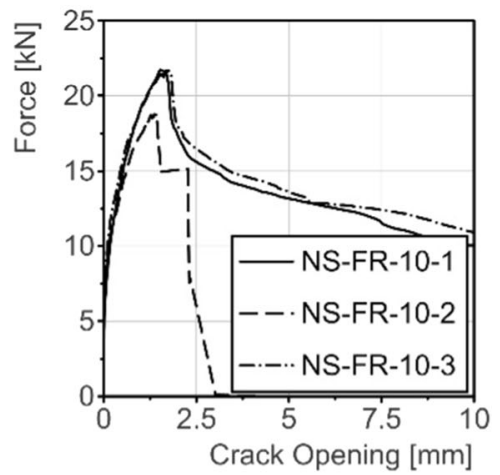

(c) NS-FR-10

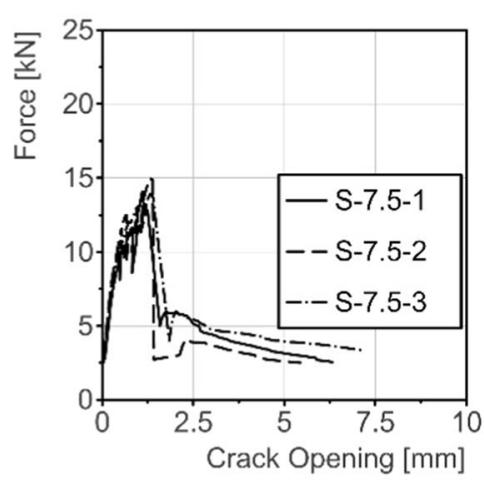

(d) S-7.5

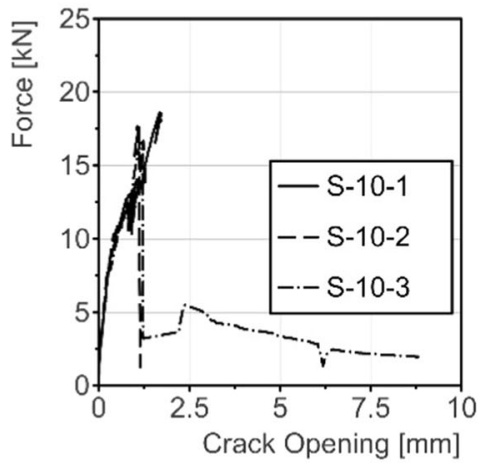

(e) S-10

Fig. 6 Force-crack opening curves for the different specimens

plates. The non-symmetric specimens prepared with UHPFRC exhibited larger out of plane displacements than the symmetric specimens did. Such displacement, however, was still relatively small compared to the one observed in the others where a non-symmetric placement of the textile was used with UHPC.

A summary of the test results is reported in Table 2. It is important to note that two tests were flagged due to a non-conforming behaviour and thus they should be discarded or taken into account with particular attention. In a more detail, specimen NS-10-2, while failing at a force value compatible with the other two tests, exhibited a crack opening at the maximum load less than $20 \%$ of what was observed in the other two tests of the same series. Despite the notched section, this specimen exhibited formation of the first crack in the bottom plate, close to the end of the overlapping zone. Thus, the deformation was concentrated in this location until reaching of the peak load, explaining the low recorded values. Nevertheless, the failure mode was compatible with what was observed in the other two specimens. Specimen NS-FR-10-2, instead, was flagged since it failed due to an early rupture of one roving, leading to both a different failure mode and a smaller maximum force than the other two specimens. Nevertheless, Table 2 reports the flagged values (between brackets) to provide a comprehensive summary. The average values are reported both considering and discarding the values of the flagged tests (the values in brackets take into consideration the flagged tests).

\section{Discussion}

To better analyse the effect that each parameter had on the overall behaviour of the specimens, the ratios of maximum force, crack opening at maximum force and out of plane displacement at maximum force between different series have been calculated. Figure 9 summarizes the results in terms of ratios of the analysed ERPs (Engineering Response Parameter, i.e. 

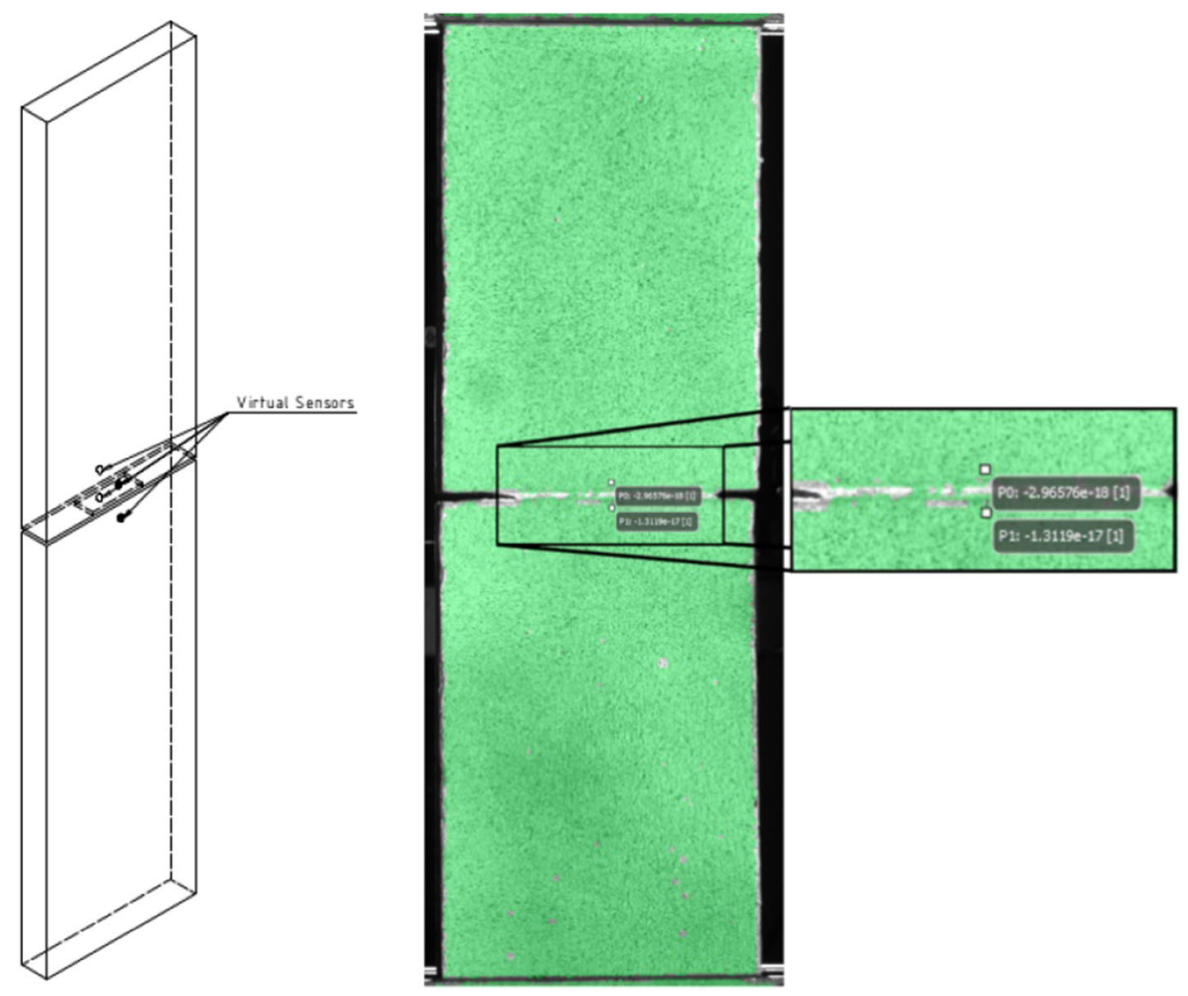

Fig. 7 Position of the out-of-plane sensors

maximum force, COD and out-of-plane displacement) to compare the test results. The values reported in the picture were calculated according to the following formulation:

$\boldsymbol{R}=\boldsymbol{E}_{R} \boldsymbol{E}^{T}$

$\boldsymbol{E}=\left[\begin{array}{c}E R P_{N S-7.5} \\ E R P_{N S-10} \\ \vdots \\ E R P_{F R-N S-7.5}\end{array}\right]$

$$
\boldsymbol{E}_{R}=\left[\begin{array}{c}
\frac{1}{E R P_{N S-7.5}} \\
\frac{1}{E R P_{N S-10}} \\
\vdots \\
\frac{1}{E R P_{F R-N S-10}}
\end{array}\right]
$$

where $E R P_{i}$ is the average ERP for each tested configuration. This results in having the column index being the numerator of the ratio while the row index is the denominator. Furthermore, some selected test results are reported in Table 3 . Focusing on the effect of the geometrical configuration, it can be noted that the average maximum force recorded by the two series with a non-symmetric layout (NS-7.5 and NS-10) and without short dispersed steel fibres did not show significant variations. This phenomenon can be attributed to the observed failure mode (spalling of the concrete cover) that prevented a full stress transfer between the textile and the surrounding cementitious matrix in the overlapping region, thus rendering the additional overlapping length useless. This conclusion is further reinforced by the results observed with symmetric specimens (S-7.5 and S-10). In this case, an increased overlapping length led to an increase in maximum force of over $20 \%$. On a side note, it is to be mentioned that specimens NS-7.5 and S-7.5 failed at comparable load levels on average (the average maximum load was 3\% higher for NS-7.5 configuration). This phenomenon is related to the failure loads associated to the two observed failure modes (splitting induced spalling and pull-out) which, coincidentally, happened to be very close. 


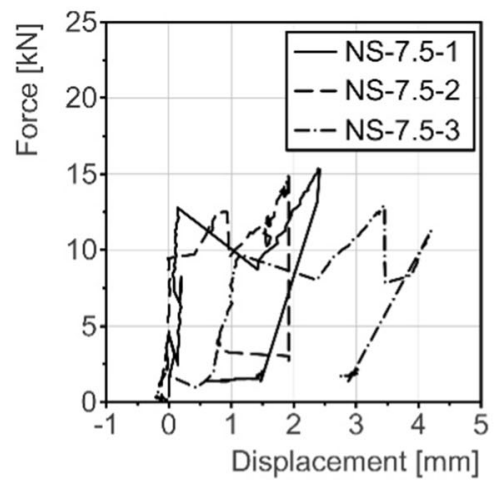

(a) NS-7.5

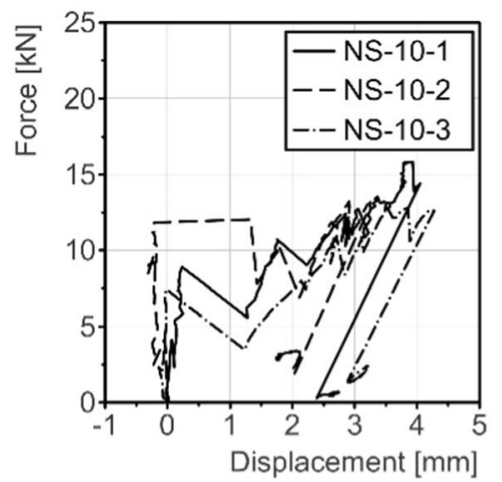

(b) NS-10

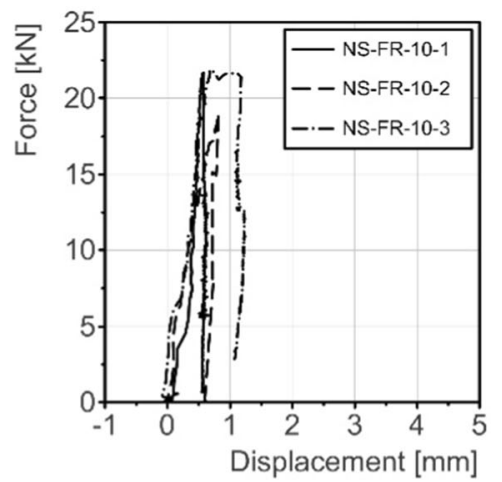

(c) NS-FR-10

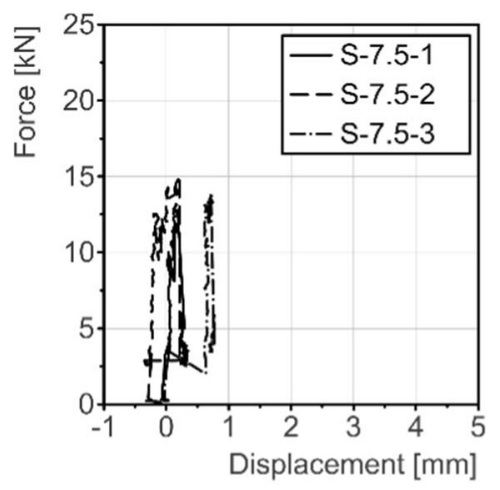

(d) S-7.5

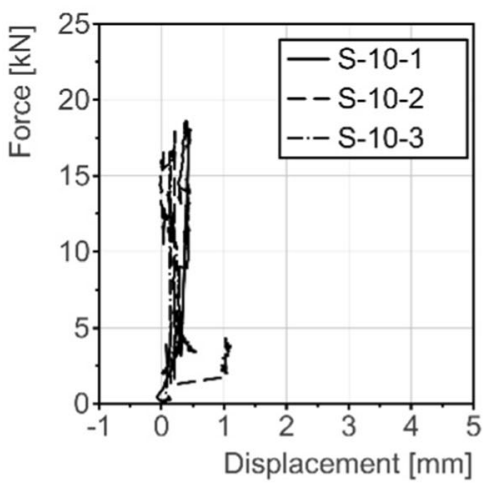

(e) S-10

Fig. 8 Force-out-of-plane displacement for the different specimens

In terms of crack opening, it is possible to see that there was no significant difference between the two non-symmetric specimens. When comparing them to the symmetric ones, a reduction of the crack opening can be seen, which was approximately $20 \%$ for both overlapping lengths. This shows that the local bondslip behaviour of the textile is actually influenced by the second layer, which provides an increase in stiffness, probably due to a better local confinement.

The most affected parameter is, as expected, the out of plane displacement. A strong reduction, more than $80 \%$ and $90 \%$ for $75 \mathrm{~mm}$ and $100 \mathrm{~mm}$ overlapping length, respectively, was recorded in symmetric configurations. The difference between the two overlapping lengths, also noticeable in the comparison of specimens NS-10 and NS-7.5, can be attributed to the increase in the internal lever arm of the overlapping zones, which generates a higher internal moment in the case of the longer overlapped textile.
An increase in the overlapping length led to an increase in the maximum force recorded by symmetric specimens. Such increase is slightly less than proportional with the increase in overlapping length $(26.3 \%$ instead of $33.3 \%$ ), hinting at the presence of a softening branch in the bond-slip law, possibly caused by the presence of the splitting cracks in the specimens. As already mentioned, no increase was observed when the non-symmetric configurations were tested. The crack opening at the maximum force did not show significant variations with the overlapping length, however, a non-negligible difference was observed in terms of out of plane displacement. Symmetric specimens, however, recorded very little values of out of plane displacement. Such difference can thus be attributed to imperfections in the specimens, which might be the result of either local imperfections in the textile or, more probably, deviations from the theoretical geometry resulting from the casting process. 
Table 2 Summary of the test results

\begin{tabular}{|c|c|c|c|}
\hline ID & $\begin{array}{l}\text { Max force } \\
(\mathrm{kN})\end{array}$ & $\begin{array}{l}\text { Crack opening at } \\
\max \text { force }(\mathrm{mm})\end{array}$ & $\begin{array}{l}\text { Out-of-plane displacement at } \\
\max \text { force }(\mathrm{mm})\end{array}$ \\
\hline NS-7.5-1 & 15.36 & 1.36 & 2.39 \\
\hline NS-7.5-2 & 14.96 & 2.25 & 1.90 \\
\hline NS-7.5-3 & 12.93 & 1.19 & 3.45 \\
\hline Average NS-7.5 & 14.42 & 1.60 & 2.58 \\
\hline NS-10-1 & 15.85 & 1.46 & 3.93 \\
\hline NS-10-2 & $(13.21)^{\mathrm{a}}$ & $(0.27)^{\mathrm{a}}$ & $(2.91)^{\mathrm{a}}$ \\
\hline NS-10-3 & 12.87 & 1.65 & 3.52 \\
\hline Average NS-10 & $14.36(13.98)^{\mathrm{b}}$ & $1.56(1.13)^{\mathrm{b}}$ & $3.73(3.45)^{\mathrm{b}}$ \\
\hline S-7.5-1 & 13.17 & 1.21 & 0.15 \\
\hline S-7.5-2 & 14.96 & 1.33 & 0.21 \\
\hline S-7.5-3 & 13.91 & 1.33 & 0.70 \\
\hline Average S-7.5 & 14.01 & 1.29 & 0.35 \\
\hline S-10-1 & 18.60 & 1.67 & 0.39 \\
\hline S-10-2 & 17.93 & 1.11 & 0.22 \\
\hline S-10-3 & 16.57 & 1.13 & 0.14 \\
\hline Average S-10 & 17.70 & 1.30 & 0.25 \\
\hline NS-FR-10-1 & 21.66 & 1.68 & 0.58 \\
\hline NS-FR-10-2 & $(18.83)^{\mathrm{a}}$ & $(1.42)^{\mathrm{a}}$ & $(0.81)^{\mathrm{a}}$ \\
\hline NS-FR-10-3 & 21.78 & 1.54 & 0.67 \\
\hline Average NS-FR-10 & $21.72(20.76)^{b}$ & $1.61(1.55)^{\mathrm{b}}$ & $0.63(0.69)^{\mathrm{b}}$ \\
\hline
\end{tabular}

${ }^{a}$ Test results that should not be taken into account due to non-conforming behaviour

${ }^{\mathrm{b}}$ Value in brackets reports the average of all tests, including flagged values
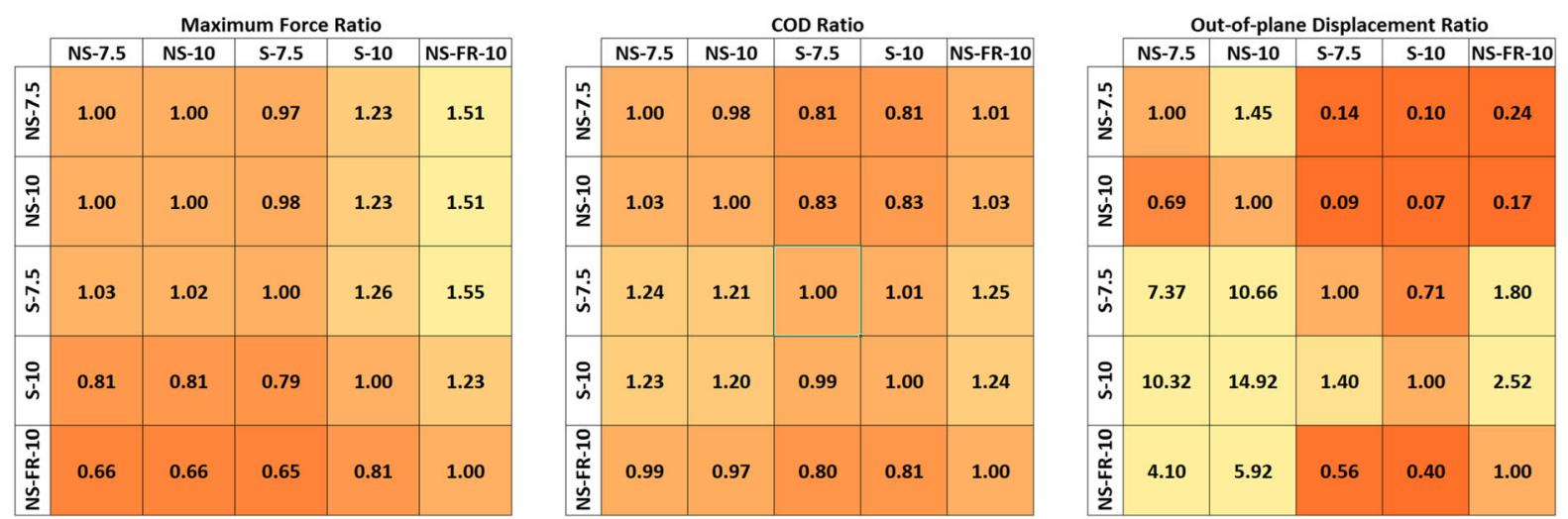

Fig. 9 Comparison of the average test results at Maximum Force. The specimen associated to the column index represents the numerator of the ratio while the one associated to the row index the denominator

The addition of short dispersed steel fibres resulted in a strong enhancement in the performance of the specimens. The maximum force increased more than $50 \%$ when compared to series NS-10 and more than $20 \%$ when compared to S-10. This shows that
UHPFRC not only enabled a better stress redistribution preventing spalling of the concrete cover, but also increased the bond between the textile and the cementitious matrix, resulting in a higher load carrying capacity. While this could be attributed to a better 
Table 3 Comparison of selected average test results

\begin{tabular}{llll}
\hline ID & Max force & Crack opening at max force & Out-of-plane displacement at max force \\
\hline NS-10/NS-7.5 & $99.6 \%(96.9 \%)^{*}$ & $97.5 \%(70.6 \%)^{*}$ & $144.6 \%(133.7 \%)^{*}$ \\
S-7.5/NS-7.5 & $97.2 \%$ & $80.6 \%$ & $13.6 \%$ \\
S-10/NS-10 & $123.3 \%(126.6 \%)^{*}$ & $83.3 \%(115.0 \%)^{*}$ & $6.7 \%(7.2 \%)^{*}$ \\
S-10/S-7.5 & $126.3 \%$ & $100.8 \%$ & $71.4 \%$ \\
NS-FR-10/NS-10 & $151.3 \%(148.5 \%)^{*}$ & $103.2 \%(137.2 \%)^{*}$ & $16.9 \%(20.0 \%)^{*}$ \\
NS-FR-10/S-10 & $122.7 \%(117.3 \%)^{*}$ & $123.8 \%(119.2 \%)^{*}$ & $252.0 \%(276.0 \%)^{*}$
\end{tabular}

*Value in brackets reports the average of all tests, including flagged values

local confinement, the fact that no significant difference was observed in terms of crack opening, comparing it to NS-10 specimens, shows that the ultimate displacement of the system was not influenced by the steel fibres, but only by the geometrical configuration. It can thus be inferred that, more than a confining effect at the edge of the overlapping zone, the performance increase of UHPFRC is probably due to an actual increase in its bonding properties, possibly caused by a reduction of the micro-cracking close to the rovings. The out of plane displacement also was strongly reduced (less than $20 \%$ of series NS-10). This phenomenon can be attributed to the absence of extensive cracking, which enabled the specimens to exhibit a higher out of plane stiffness. Such parameter was more than two times bigger than what was observed, on average, for symmetric specimens with the same overlapping length.

From a design perspective, a symmetric configuration should always be used. This can be a challenge in TRC structures where only a single layer is used. Nevertheless, whenever possible, joining textile layers should be done with particular care in detailing the overlapping regions. Possible detailing layouts are presented in Fig. 10. If such solutions are not possible, the introduction of short dispersed fibres can outbalance the beneficial effect of a symmetric configuration and prevent undesired failure modes. This consideration is also in-line with existing regulations for reinforced concrete structures [36, 37], which require the presence of transversal reinforcement in the overlapping regions. In traditional reinforced concrete structures stirrups are used as transversal reinforcement, however, in the case of TRC elements, this is not a viable solution. Dispersed fibres admixed to the cementitious matrix, on the other hand, can resist
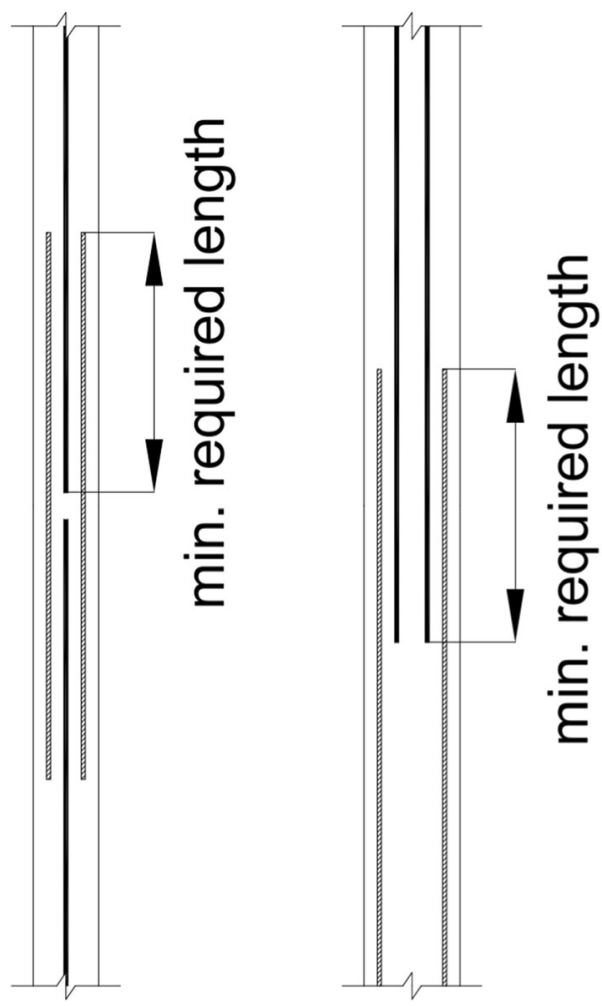

Fig. 10 Schematic representation of recommendable geometrical layouts

transverse tension forces that arise in the overlapping region, thus providing an effect similar to the presence of transversal reinforcement.

\section{Conclusions}

An experimental campaign aimed at testing overlapped textile joints in TRC structures was performed 
at the structural lab of Carinthia University of Applied Sciences. The effects of several parameters were investigated such as geometrical configuration, overlapping length and presence of short dispersed steel fibres. From the evaluation of the results the following conclusions can be drawn:

- Symmetric configurations should always be preferred to non-symmetric ones because the latter may result in a premature failure of the joint due to the increase of transverse stresses promoting splitting failure and resulting in spalling of the concrete cover. Furthermore, such configurations exhibit a higher stiffness, thus concentrating the deformations in less critical areas of the TRC element. Lastly, symmetric configurations, due to the absence of an internal moment, prevent undesired out of plane deformations of the TRC thin element.

- A longer overlapping length of the textile was effective only when symmetric configurations were tested. Non-symmetric configurations may prevent a full development of bond between the textile and the cementitious matrix.

- The introduction of short dispersed steel fibres in the concrete matrix enabled to achieve very high performances even if a non-symmetric configuration was employed, resulting in an increase in the pull-out load of more than $50 \%$ and $20 \%$ when compared to non-symmetric and symmetric specimens without steel fibres, respectively.

- The enhanced tension properties of UHPFRC, compared to UHPC, resulted in an increased performance of the specimens in terms of out of plane deformation. Preventing a diffused crack pattern of the TRC elements resulted in a higher out of plane stiffness, thus reducing the out of plane displacement.

Acknowledgments The Authors would like to thank the companies solidian $\mathrm{GmbH}$ and w\&p Beton Holding $\mathrm{GmbH}$ for the material supply.

Authors' contribution Edoardo Rossi: Conceptualization, Formal analysis, Investigation, Data curation, Writing Original draft, Visualization. Norbert Randl: Conceptualization, Resources, Writing - Review and edit, Supervision, Project administration, Funding acquisition. Peter Harsányi: Conceptualization, Investigation, Writing - Review and edit. Tamás Mészöly: Conceptualization, Investigation, Writing - Review and edit.
Funding Open access funding provided by Carinthia University of Applied Sciences (CUAS). This work has been partially completed thanks to the CON_FIT project "Performance-oriented application of fibre and textilereinforced high performance concretes for structural retrofit" funded with support of The Austrian Research Promotion Agency, FFG, grant no. 866881.

Data availability All the data supporting the findings of this study are available from the corresponding author upon reasonable request.

\section{Declarations}

Conflict of interest The Authors have no conflict of interest to declare that are relevant to the content of this article.

Open Access This article is licensed under a Creative Commons Attribution 4.0 International License, which permits use, sharing, adaptation, distribution and reproduction in any medium or format, as long as you give appropriate credit to the original author(s) and the source, provide a link to the Creative Commons licence, and indicate if changes were made. The images or other third party material in this article are included in the article's Creative Commons licence, unless indicated otherwise in a credit line to the material. If material is not included in the article's Creative Commons licence and your intended use is not permitted by statutory regulation or exceeds the permitted use, you will need to obtain permission directly from the copyright holder. To view a copy of this licence, visit http://creativecommons.org/licenses/by/4.0/.

\section{References}

1. Hegger J, Voss S (2008) Investigations on the bearing behaviour and application potential of textile reinforced concrete. Eng Struct 30(7):2050-2056. https://doi.org/10. 1016/j.engstruct.2008.01.006

2. Ehlig D, Schladitz F, Frenzel M, Curbach M (2012) Textilbeton - Ausgeführte Projekte im Überblick. BetonStahlbetonbau 107(11):777-785. https://doi.org/10.1002/ best. 201200034

3. Rempel S, Hegger J (2015) "Slender facade structures made of textile-reinforced high performance concrete", in 11th International Symposium on Ferrocement FERRO-11 in connection with the 3rd ICTRC. Aachen, Germany, pp 7-10

4. Sharei E, Scholzen A, Hegger J, Chudoba R (2017) Structural behavior of a lightweight, textile-reinforced concrete barrel vault shell. Compos Struct 171:505-514. https://doi. org/10.1016/j.compstruct.2017.03.069

5. Rempel S, Kulas C, Will N, Bielak J (2018) Extremely light and slender precast pedestrian-bridge made out of textilereinforced concrete (TRC). In: High tech concrete: where technology and engineering meet. Springer, Cham, pp 2530-2537

6. Ombres L (2011) Flexural analysis of reinforced concrete beams strengthened with a cement based high strength 
composite material. Compos Struct 94(1):143-155. https:// doi.org/10.1016/j.compstruct.2011.07.008

7. Contamine R, Si Larbi A and Hamelin P (2013) "Identifying the contributing mechanisms of textile reinforced concrete (TRC) in the case of shear repairing damaged and reinforced concrete beams," Eng. Struct. 46; 447-458. https://doi.org/10.1016/j.engstruct.2012.07.024.

8. Awani O, El-Maaddawy T, Ismail N (2017) Fabric-reinforced cementitious matrix: A promising strengthening technique for concrete structures. Constr Build Mater 132:94-111. https://doi.org/10.1016/j.conbuildmat.2016. 11.125

9. Nobili A and Falope FO (2017) "Impregnated carbon fabric-reinforced cementitious matrix composite for rehabilitation of the Finale Emilia hospital roofs: case study." J. Compos. Constr. 21(4). https://doi.org/10.1061/(ASCE)CC. 1943-5614.0000780.

10. Bencardino F, Carloni C, Condello A, Focacci F, Napoli A, Realfonzo R (2018) Flexural behaviour of RC members strengthened with FRCM: State-of-the-art and predictive formulas. Compos Part B Eng 148:132-148. https://doi.org/ 10.1016/j.compositesb.2018.04.051

11. Muresan A-M, Zwicky D (2018) Dimensioning the flexural strengthening of concrete slabs with textile reinforced mortar - literature data evaluation. In: Proceedings of IABSE conference 2018 "Engineering the past, to meet the needs of the future". Copenhagen, Denmark, 25-27 June 2018

12. Elsanadedy HM, Abbas H, Almusallam TH, Al-Salloum YA (2019) Organic versus inorganic matrix composites for bond-critical strengthening applications of RC structures State-of-the-art review. Compos Part B Eng 174:106947. https://doi.org/10.1016/j.compositesb.2019.106947

13. Tarque N, Salsavilca J, Yacila J, Camata G (2019) Multicriteria analysis of five reinforcement options for Peruvian confined masonry walls. Earthq Struct 17(2):205-219. https://doi.org/10.12989/EAS.2019.17.2.205

14. Yacila J, Salsavilca J, Tarque N, Camata G (2019) Experimental assessment of confined masonry walls retrofitted with SRG under lateral cyclic loads. Eng Struct 199:109555. https://doi.org/10.1016/j.engstruct.2019.109555

15. Angiolilli M, Gregori A, Pathirage M, Cusatis G (2020) Fiber Reinforced Cementitious Matrix (FRCM) for strengthening historical stone masonry structures: Experiments and computations. Eng Struct 224:111102. https:// doi.org/10.1016/j.engstruct.2020.111102

16. Ferrara G, Caggegi C, Martinelli E, Gabor A (2020) Shear capacity of masonry walls externally strengthened using Flax-TRM composite systems: experimental tests and comparative assessment. Constr Build Mater 261:120490. https://doi.org/10.1016/j.conbuildmat.2020.120490

17. Koutas LN, Bournas DA (2020) Confinement of masonry columns with textile-reinforced mortar jackets. Constr Build Mater 258:120343. https://doi.org/10.1016/j. conbuildmat.2020.120343

18. Salsavilca J, Yacila J, Tarque N, Camata G (2020) Experimental and analytical bond behaviour of masonry strengthened with steel reinforced grout (SRG). Constr Build Mater 238:117635. https://doi.org/10.1016/j. conbuildmat.2019.117635
19. (2016) RILEM Technical Committee 232-TDT (Wolfgang Brameshuber), "Recommendation of RILEM TC 232-TDT: test methods and design of textile reinforced concrete: Uniaxial tensile test: test method to determine the load bearing behavior of tensile specimens made of textile reinforced concrete," Mater. Struct. 49(12), 4923-4927. https://doi.org/10.1617/s11527-016-0839-z.

20. Hartig J, Jesse F, Schicktanz K, Häußler-Combe U (2012) Influence of experimental setups on the apparent uniaxial tensile load-bearing capacity of Textile Reinforced Concrete specimens. Mater Struct 45(3):433-446. https://doi. org/10.1617/s11527-011-9775-0

21. de Felice $G$ et al (2018) Recommendation of RILEM Technical Committee 250-CSM: Test method for Textile Reinforced Mortar to substrate bond characterization. Mater Struct 51(4):95. https://doi.org/10.1617/s11527-018-1216$\mathrm{x}$

22. Xu S, Krüger M, Reinhardt H-W, Ožbolt J (2004) Bond characteristics of carbon, alkali resistant glass and aramid textiles in mortar. J Mater Civ Eng 16(4):356-364. https:// doi.org/10.1061/(ASCE)0899-1561(2004)16:4(356)

23. Li Y, Bielak J, Hegger J, Chudoba R (2018) An incremental inverse analysis procedure for identification of bond-slip laws in composites applied to textile reinforced concrete. Compos Part B Eng 137:111-122. https://doi.org/10.1016/j. compositesb.2017.11.014

24. Ebead U, Younis A (2019) Pull-off characterization of FRCM/Concrete interface. Compos Part B Eng 165:545-553. https://doi.org/10.1016/j.compositesb.2019. 02.025

25. Lorenz E and Ortlepp R (2011) "Untersuchungen zur Bestimmung der Übergreifungslängen textiler Bewehrungen aus Carbon in Textilbeton (TRC)," in 6th Colloqium on Textile Reinforced Structures. 85-102.

26. Azzam A and Richter M (2011) "Investigation of stress transfer behavior in textile reinforced concrete with application to reinforcement overlapping and development lengths," in 6th Colloqium on Textile Reinforced Structures. 103-116.

27. Donnini J, Chiappini G, Lancioni G, Corinaldesi V (2019) Tensile behaviour of glass FRCM systems with fabrics' overlap: Experimental results and numerical modeling. Compos Struct 212:398-411. https://doi.org/10.1016/j. compstruct.2019.01.053

28. Vlach T, Laiblová L, Řepka J, Jirkalová Z, Hájek P (2019) Experimental verification of impregnated textile reinforcement splicing by overlapping. Acta Polytech CTU Proc 22:128-132. https://doi.org/10.14311/APP.2019.22.0128

29. "solidian GRID Q142/142-CCE-25 Technical data sheet."

30. Randl N, Steiner T, Ofner S, Baumgartner E, Mészöly T (2014) Development of UHPC mixtures from an ecological point of view. Constr Build Mater 67:373-378. https://doi. org/10.1016/j.conbuildmat.2013.12.102

31. Ricker M, Häusler F, Randl N (2017) Punching strength of flat plates reinforced with UHPC and double-headed studs. Eng Struct 136:345-354. https://doi.org/10.1016/j. engstruct.2017.01.018

32. Mészöly T, Randl N (2018) Shear behavior of fiber-reinforced ultra-high performance concrete beams. Eng Struct 168:119-127. https://doi.org/10.1016/j.engstruct.2018.04. 075 
33. Mészöly T, Ofner S, Randl N (2020) Effect of combining fiber and textile reinforcement on the flexural behavior of UHPC plates. Adv Mater Sci Eng 2020:1-8. https://doi.org/ 10.1155/2020/9891619

34. Randl N, Harsànyi P (2018) Developing optimized strengthening systems for shear-deficient concrete members. Struct Concr 19(1):116-128. https://doi.org/10.1002/ suco.201600187

35. Preinstorfer P, Kromoser B (2020) Influence of geometrical parameters on the splitting forces in textile-reinforced concrete. Mater Struct 53(6). https://doi.org/10.1617/ s11527-020-01590-w
36. (2004) European Committee for Standardization, "Eurocode 2: Design of concrete structures - Part 1-1: General rules for buildings"

37. (2013) International Federation for Structural Concrete (fib), "fib Model Code for Concrete Structures 2010", Ernst \& Sohn

Publisher's Note Springer Nature remains neutral with regard to jurisdictional claims in published maps and institutional affiliations. 